Journal of Social Sciences 6 (1): 99-112, 2010

ISSN 1549-3652

(C) 2010 Science Publications

\title{
Cultural Issues in the Business World: An Anthropological Perspective
}

\author{
Michael P. Lillis and Robert Guang Tian \\ Department of Business, Medaille College, New York
}

\begin{abstract}
The significance of cultural influence on business has been widely recognized in both academic and business circles. A number of authors suggest that an anthropological approach is the most appropriate way to study cultural factors and assess their impact on an organizational environment. This investigation draws attention to several important cultural issues in business utilizing an anthropological perspective. It probes the relationship between culture and human behavior, between organizational values and organizational behavior, and identifies several effective methods for managing cultural differences that often permeate an organization's workforce.
\end{abstract}

Key words: Anthropology, culture and behavior, manage culture difference, organizational behavior

\section{INTRODUCTION}

The core for anthropology as a social science is about culture and its relationship with human behavior. Although there are many different definitions of culture by scholars from different fields, such as political scientists, historians, psychologists, anthropologists, sociologists and so on, the common points by crossfield scholars are clear. The essential core of culture consists of traditional ideas that are historically derived and selected and especially their attached values. On the one hand culture systems may be considered as products of action or as conditioning elements of further action. It consists of patterns, explicit and implicit, of and for behavior acquired and transmitted by symbols, constituting the distinctive achievements of human groups, including their embodiments in artifacts (Kroeber and Kluckhohn, 1952).

More specifically, culture consists of traditional values and beliefs, ideas, customs, skills, arts and language of a specific group in a given period. Culture provides people with a sense of identity and an understanding acceptable behavior in the society. In the twentieth century, "culture" emerged as a concept central to anthropology, encompassing all human phenomena that are not purely results of human genetics. Specifically, the term culture to American anthropologists has two meanings: (1) the evolved human capacity to classify and represent experiences with symbols, it also refers to human capacity to act imaginatively and creatively; (2) the distinct ways that people living in different parts of the world classified and represented their experiences and acted creatively. Following World War II, the term became important, although with different meanings, in other disciplines such as sociology, cultural studies, organizational psychology and management studies (Wikipedia, 2009).

Anthropologists' interest in culture studies is originally for academic purpose but quickly extends to business applications. The result of anthropological study on culture has been widely applied in various fields in real business world. In the real business world, a good understanding of cultural values in general and specific individual cultural characteristics in particular can lead to success in the global market and economy. Otherwise, cultural misunderstandings can be counterproductive for individual development, organizational effectiveness and profits, because cultural factors influence people motives, brand comprehension, attitude and intention to purchase. Therefore it is important that we clearly understand the fact that as members of the global marketplace, although our effectiveness depends on many factors the primary one among them should be the capacity to understand our cultural preferences and how they influence and are influenced by those from other parts of the world (Hofstede, 1980; Lillis and Tian, 2009; Charles and Tian, 2003).

Cultural factor plays an important role in the real business world. This role cannot be replaced by any other factors nor can it be ignored by any business organizations. In this study we will focus on discussion of cultural issues in the business world. After this short introduction we first present an anthropological approach to culture studies, followed by a discussion of the relationship between culture and human behavior, then a discussion of the relationship between culture 
and organization behavior and finally we will probe the various effective means to manage the cultural difference in business practice.

Anthropological approach to culture: For anthropologists, culture is the integrated system of socially acquired values, beliefs and rules of conduct which delimit the range of accepted behaviors in any given society. Cultural differences distinguish societies from one another. One of the first anthropological definitions of the term was given by Sir Tylor (1974) in the late 19th century. By Kroeber and Kluckhohn (1952) had cataloged 164 different definitions of the word. In anthropology, the nature of culture is consisted of various ingredients or components, such as norms, customs, mores, conventions, language, religion and so on. Each of these ingredients or components plays an equally important role in determining the nature and values of a particular culture.

According to Perraro, the science of anthropology attempts to document the great variations in cultural forms while looking for both the common strands that are found in and the general principles that apply to, all cultures. Anthropology, especially cultural anthropology, seeks to understand how and why peoples of the world differ in various ways as well as how and why peoples of the world share certain similarities. It is not at all unusual for people to assume that their own ways of thinking and acting are unquestionably rational normal or human. Cultural anthropological study provides us a look at the enormous variations in thinking and acting found in the world today due to the cultural differences and at same time anthropological literature has documented many different solutions generated for solving the same problems cross-culturally. Therefore, anthropologists do more than simply document the enormous variations in human cultures by identifying and describing the commonalities of humans amid the great diversity, which are the regularities found in all cultural contexts regardless of how different those contexts might appear at first glance (Ferraro, 2005).

Anthropologists have traditionally used a qualitative research approach to study human behaviors in different cultures. Such an approach is well suited to many of the complex questions confronting researchers interested in quality and culture. Qualitative research, more than just a set of data collection methods, is an approach that seeks to understand events, activities, norms and values from the perspective of the people who are being studied, anthropologists refer this way of research as the Emic approach. Qualitative research emphasizes context and the ways in which features of a specific situation or setting impact upon the phenomenon under study. Because qualitative research tends to be flexible and iterative, it allows for the discovery of unexpectedly important topics that may not have been visible had the researcher been limited to a pre-defined set of questions or data collection methods (Walle, 2001).

Anthropologists also use a number of more structured data collection techniques to study culture. The most common of these techniques include free listing, pile sorts and rank order methods. These techniques produce numerical, quantifiable data but are included in the qualitative research 'toolbox' because their purpose is to identify and analyze cultural domains from the point of view of respondents. These methods have been used extensively in the field of international health, but much less so closer to home. Cultural consensus analysis is another method used by anthropologists to identify groups with shared values and which may be especially useful to those interested in studying organizational culture (Weller and Romney, 1988).

Business anthropology is the exploration of the culture and social framework of business organizations. As such, it directs explicit attention to the observable activities and interactions, communicated information and material artifacts that form the social experience (Rousseau, 1990). Techniques for assessment typically rely on long term, intensive field studies that attempt to understand the development and behavior of people who are members of a social unit. Types of methodologies most commonly used in connection with anthropological research try to get the researcher to experience firsthand as much of the organization as possible, frequently emphasize the importance of ethnography in its approach and methodology.

Given the central role that culture plays in business anthropology, it is important to have a definition on which to base one's understanding. Some suggests that in order to understand the actions and commitments of individuals and groups, one must concentrate analytic attention on the symbols, languages, beliefs, visions, ideologies and myths that are generated and sustained by organizations (Pettigrew, 1979). However, as the writings of other authors point out, there have been numerous debates about what best represents the elements and attributes of organizational culture. Much of the literature on culture directs attention to elements that are found inside the minds of organizational members (Schein, 1990). On author suggests that "an organization's behavior and decisions are almost predetermined by the pattern of basic assumptions existing in the organization" (Ott, 1989). By 
implication, it would follow then that individual behavior is largely controlled by a cognitive process, determining the manner in which decisions are made and activities are performed.

Although there have been many approaches to the term organizational culture, a majority of them, including those discussed above, are consistent with the concept of an "ideational" system put forth by cultural anthropologists (Allaire and Firsirotu, 1984). As such, organizational culture is conceptualized as a cognitive construct, a product of the mind of it's members and a set of shared meanings and symbols (Geertz, 1973). For instance, both Osgood (1951a) and Taylor (1948) characterize culture as a "mental phenomenon" that exists primarily in the mind of the culture bearer (Osgood, 1951a). Similarly, Beals and Hoijer (1953) write: "culture is an abstraction from behavior and not to be confused with acts of behavior or with material artifacts" (Beals and Hoijer, 1953). Consistent with this perspective, Edgar Schein suggests culture represents a pattern of basic assumptions that determine individual patterns of "perceiving, thinking, feeling and behaving" that provide a better understanding of events within an organization (Schein, 1990).

A second school of cultural anthropology, the "adaptationist" perspective views culture as that which is directly observable about the organization or, in other words, what an organization does and how it does it (Keesing, 1974). Here culture is viewed as an outcome that comprises the objective and directly observable reality. The task of researchers, under this model, is to describe the properties of manifest activities, in ways which identify one or more styles implied by organizational practices. Culture then represents those things that are distinctive about what is observed in an organization.

Consistent with the adaptationist perspective, a "visual" interpretation would suggest that we can increase our understanding of a culture by examining the objects that surround us as they provide unique insights into the people and societies that use them (Prown, 2001; Schlereth, 1985; Berger, 1992). For example, just as decorative arts serve as insightful indices of a society's values, so do the variety of physical artifacts that surround an organizational environment (Feldhusen, 2008). Another interpretation of culture draws attention to a broader "materialistic" view, which encompasses a theoretical commitment to the casual primacy of infrastructural variables in explaining sociocultural systems, a principle known as infrastructural determinism (Harris, 1968). According to this view, the infrastructure is seen as the base of society and includes strategies by which people relate to the material conditions of human life.

Consequently, any causes for similarities and differences in behavior and thought found among human populations can be explained by how individuals "relate to and reproduce in the environment; how they produce food, tools and shelter and the technologies they employ in doing so" (Murphy and Margolis, 1995). The common assumption underlying material culture research is that objects made or modified by humans, consciously or unconsciously, directly or indirectly, reflect the belief patters of individuals who made, commissioned, purchased, or used them and, by extension, the belief patterns of the larger society of which they are a part (Schlereth, 1999).

Ultimately, to fully understand how people think and behave in the context of an organization, anthropologists need to gain insights from both perspectives of culture. Consistent with the ideationalist, culture is defined as a cognitive construct as it directs attention to the "thinking practices" of organizational members. However, in keeping with the adaptationist perspective, it is necessary to search for a logical, cohesive pattern in the myriad of observable behaviors. Any behavior patterns that emerge are reflective of organizational tendencies for which inferences about an organization's culture might be based. By viewing culture as a cognitive process that is also expressed behaviorally, a clearer understanding of a culture will emerge. Therefore, in order to describe culture in all its richness and complexity, the variety of views that are held about the essence of organizational culture need to be incorporated-from the visible to invisible patterns of thinking and behaving.

Culture is seen as having many components; layered along a continuum of unconscious-conscious processes. As shown in Fig. 1, these layers of culture can range from highly internalized and often unconscious facets of culture (implicit assumptions) to material artifacts and other directly observable manifestations. These layers represent the primary elements found among organizational researchers' conceptualizations of culture. At the deepest level, unconscious assumptions represent what Schein identified as "implicit assumptions", taken-for-granted beliefs, perceptions, thoughts and feelings that tell group members how to perceive, think about and feel about things (Schein, 1993). Alternatively, at the outermost level, one can observe "concrete cultural forms", these include: Symbols (physical artifacts, settings), language (jargon, gestures, humor, slogans), narratives (stories and myths) and practices (rituals, taboos, rites, ceremonials) (Trice and Beyer, 1993). 


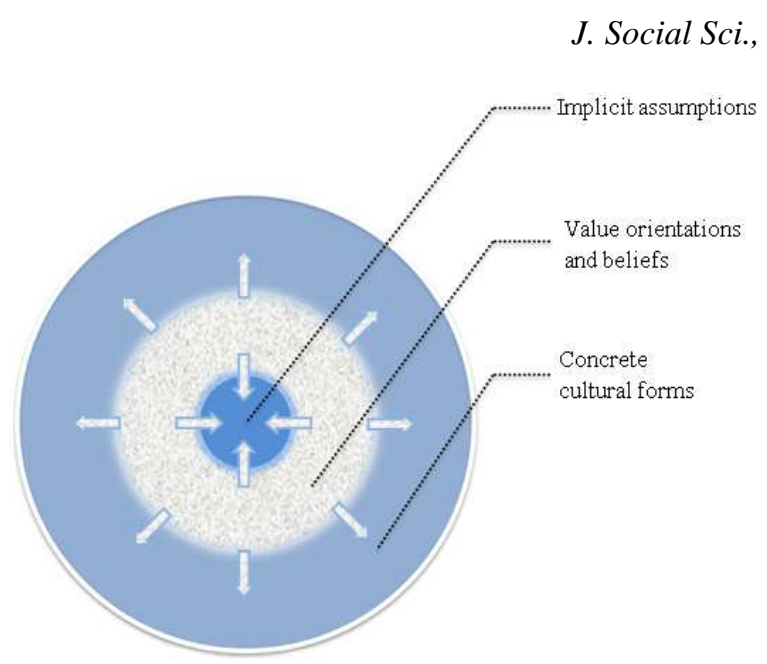

Fig. 1: Layers of culture. Source: Schein (1985)

Permeating the inner and outermost layers, value orientations, represent shared perceptions of highlyregarded standards of behavior and priorities for action. As suggested by the arrows in the Fig. 1, values represent a vital impetus for both visible and invisible expressions of culture. As such, values can be deciphered through the directly observable world as well as through the implicit shared meanings and understandings that guide behavior. Frequently, value orientations are made explicit through an organizational mission statement or vision proclamation. Under these circumstances, investigators must be careful and examine whether these articulated values are congruent with underlying assumptions and do not just represent aspirations for the future. Moreover, it is reasonable to expect that as values become second nature to members of a social unit, they become less obvious in the physical world as they migrate to the level of unconscious assumptions. Ultimately, in order to understand what is valued by an organization, researchers must explore culture across the continuum, giving consideration to both highly observable elements and unconscious processes.

In the field of anthropology, understanding culture is viewed as ethnography's primary contribution (Bickman and Rog, 2009). But a question remains as to the best means for assessing organizational culture. Using Fig. 1, it can be argued that a layered model of culture calls for a variety of techniques to help aid in its understanding. For example, at the level of assumptions, culture can be a highly subjective, unconscious process and therefore not amenable to standardized assessment methods. Under such circumstances, overt behaviors and physical evidence may not be sufficient sources of culture data. The inaccessibility, depth, or unconscious quality of

assumptions provides good support for the use of qualitative methods. To that end, some writers have argued that assumptions can be so deeply embedded that only a complex interactive process of joint inquiry between insiders and outsiders can bring them to the surface (Schein, 1984). Clearly this kind of interactive probing is essential for less visible manifestations of culture. Such observations led some to conclude that as the elements of culture become more conscious or visible, observations by outsiders and responses to structured instruments become more appropriate (Rousseau, 1990).

Culture and human behavior: We believe that there are many factors influence human behavior, such as biological, genetic, psychological and environmental factors, however cultural factors play a more important role than others (Erchak, 1998). Culture influences all aspects of human's lives. Individuals use culture to explain similarities within the same group of people and differences among various groups of people. Culture involves both subjective and objective elements. Attitudes, values, beliefs, opinions, behaviors are subjective, while clothes, food, utensils, architecture are objective (Triandis, 1972). Culture is not a static entity but is ever-evolving. What we commonly know as "the generation gap" is in fact a cultural difference as it refers to different patterns of behavior, different ways of life and being for people who are raised in different periods of time. Cultures provide rules for human beings to live, to tell people how to interact, work and play with each other. Of all the possible things people could do, culture facilitates to limit what individuals should do in order to survive in the environment in which they live. Culture is communicated across generations. Moreover, culture enables behavior, allowing it to be created or invented at same time it constrains and restricts behavior (Matsumoto, 2006).

Human behavior is often complicated. Behavior scientist Dr. Dennis O'Neil suggests that in order to understand and comprehend the interaction among individuals in various situations, it is useful for us to think in terms of a distinction between ideal, actual and believed behavior. For O'Neil, ideal behavior is what people think they should be doing and what they want others to believe they are doing. Actual behavior is what is really going on. Believed behavior is what people honestly think they are doing. In everyday life, our behaviors are often different from what we believe them to be at that time. For instance, many North American husbands assume that they do roughly half of the work of cleaning and maintaining their home, but their wives would probably dispute that assertion. Does 
this mean that the husbands are not telling the truth? For O'Neil the answer is "no", it usually means that the husbands' perception of what they are doing may not be realistic in this case. Anthropologists are not only interested in learning about actual behavior. Ideal and believed behavior also can tell us much about how a society and its culture work (O'Neil, 2009).

Definitions of culture are described within the framework of a social group's view of reality. A key question however relates to whether or not a microanalytic observation and interpretation of individual behavior can provide a basis for drawing inferences about macro-level group-based behavior patterns. Allaire and Firsirotu (1984) notion of "partial replication", for instance, implies that a simple communality of personal meanings evolves among the several actors in a social system, which works to homogenize their world views and facilitate their interactions. Hence, observations of inter-individual consistency of behavior may be taken as indicative of shared cognitive structures (beliefs, concepts, values) at a collective level of aggregation. Inter-individual/intraorganizational consistency of behaviors is thus expressive (and, in fact, descriptive) of organizational culture.

To what extent however is inter-individual consistency a significant distinction between cultural and non-cultural elements? In other words can behavior that is particular to a single individual be considered part of an organization's culture? A number of authors have suggested that it takes two or more people for a phenomenon to be considered an element of culture (Osgood, 1951b; Durkheim, 1938). In an attempt to resolve this issue, White suggests that the behavior of an individual is cultural to the extent it is considered in an extrosomatic context, i.e. in terms of its relationship to the acts of others rather than in terms of its relationship to the human organism (Whilte, 1959). Specification of such criteria, one posits, provides an anthropologist with sound conceptual means for understanding organizational "cultures", and of generalizing about and predicting behavior without, however, requiring commitments to belief in the "reality" of those "cultures".

The conception of culture discussed by scholars is beyond academic scope but more towards business practice. For instance, Hofstede (1980) most cited book on culture is written not primarily out of academic theory, but out of his study of the practical problems faced by one particular modern corporation (IBM), which exists across national and cultural boundaries. An American boss will find that relations with Saudi employees will become strained and difficult if she or he simply treats them as though they were Americans (Hofstede, 1980). For anthropologists then, culture is conceptualized as a group level phenomenon that is "shared" in the sense that there is consensus among members in a social system (Wright, 1994). The question raised in the organizational studies literature is whether these shared understandings are in line with the shared vision at the top of the organization, frequently identified as an organization's “corporate culture" (Deal and Kennedy, 1982). Geertz (1973) describes culture as follows:

The concept of culture I espouse....is essentially a semiotic one. Believing, with Max Weber, that man [sic] is an animal suspended in webs of significance he himself has spun, I take culture to be those webs and the analysis of it to be therefore not an experimental science in search of law but an interpretive one in search of meaning

Geertz (1973) 'web of meaning' represents an interpretive process where individual behavior comes to be understood within a broader context. To that end, Peters and Waterman (1986) notion of "strong culture" can be taken as the extent of coherence between the corporate culture and collective meanings at lower levels of the organization (Peters and Waterman, 1986; Wright, 1994).

Although culture is frequently described as an organizational level phenomenon, some researchers have raised questions about the assumption that the locus of culture is found at the organizational level of analysis. Some researchers argue that argued that when observing 'natives' in a particular culture, observations could reflect characteristics of persons, dyads, groups, or the entire organization.. Similarly, some suggest that organizations may form subcultures, which represent lower-level collectives, as in a department or a division level (Louis, 1985). Therefore, to fully understand human behavior, it is necessary to trace linkages between individual behavior and the appropriate level of analysis (Dansereau and Alutto, 1990). In other words, expressions of culture are only decipherable if within- and between-group variation provides sufficient evidence of an effect at a particular level of analysis.

Anthropological approach is a very effective way to assess the impact of culture on product design, product purchase and product usage. We agree with Mariampolski that culture is important as a heuristic principle for describing and classifying human behaviors, it is also an analytic concept to be used for explaining how individuals' choice result from the 
interpersonal influences and symbolic universe that delineate everyday life. According to Mariampolski culture operates on both the material and nonmaterial levels of human experience, which serves as the foundation for the behaviors, meanings and tolls of all human collectives. To Mariampolski cultural tools refer to all of the physical components of group's life experiences, which include technology and materials, as well as the fundamental rules, codes and techniques for accomplishing daily affairs. Cultural behaviors (no matter they are practical, goal-oriented with, sensate, or mystical) are the totality of activities associated with membership in a group. Cultural meanings refer to the sense-making process: how people intellectually or emotionally understand the purposes, implications and associations that underline all of human behaviors and the tools individuals use in everyday life (Mariampolski, 2005).

Anthropologist Serrie (1986) has provided an excellent example of how an anthropological understanding of local cultural patterns in southern Mexico prevented the costly mistake of mass producing a solar cooker developed for this area. Designed to reduce the use of firewood for cooking by encouraging the use of solar energy, these solar stoves, with the assistance of a four-foot parabolic reflector, produced levels of heat comparable to a wood fire. Although initial demonstrations of the cooker caught the interest of the local people, a number of cultural features militated against the widespread acceptance of this technological device. To illustrate: (1) the major part of the cooking in this part of Mexico is done early in the morning and in the early evening, at those times when solar radiation is at its lowest level and (2) although the solar stove was very effective for boiling beans and soup, it was inadequate for cooking tortillas, a basic staple in the local diet. Thus, for these and other reasons, it was decided not to mass-produce and market the solar cookers because, even though the cooker worked well technically, it made little sense culturally (Serrie, 1986; Ferraro, 2005).

Organizational culture and behavior: As discussed previously, culture is a set of values that are adopted by people who live together in a same place. For example, when we refer to a particular culture with a prefixed adjective word of a place (such as Canadian culture, Chinese culture, or American culture) we are talking about the shared traits of the people who live in that particular place, their values, their lifestyles and their rituals. If we apply this conception of culture with the prefixed word "organization", we are referring to the rules and the underlying values of an organization that are constant and apply to all employees, without any bias or favoritism. It is the foundation of the overt and covert behaviors and reactions of all people that work in the same organization (Kulkarni, 2009).

Both ideational and material definitions provide a useful starting point for enhancing one's cultural understanding. A critical step in interpreting culture is to identify the major values that an organization advocates. But why do organizations advocate certain values and what are the implications for employee behavior? As one might expect, many companies establish rules and support norms in the hope that certain values shape and influence the way organizational members behave. For example, at Microsoft and Nokia, workers strive for innovation and creativity; at Dell and Southwest, employees make every effort to provide high-quality customer service; workers at Toyota and Nordrstom, build product reliability and excellence into new and existing product offerings and employees at Cisco Systems and Walmart continually look for ways of lowering their cost structure and increasing workforce productivity. In these examples, espoused values translate into actual standards of behavior that have a significant impact on an organization's bottom line.

Organizational culture can be separated into 3 tiers on an organizational culture pyramid. The lowest tier is that of artifacts and behaviors, which represent the most tangible aspects of organizational culture. The physical layout of the workplace and the displayed behaviors of the employees comprise this level. The middle tier is that of values which influence the assumptions and behaviors of employees. Hence they are tangible. The top tier is that of assumptions and beliefs which are the most crucial and intangible aspect of organizational culture. Meanwhile, assumptions and beliefs are toughest to be absorbed by the employees and take time to be formatted. But once the employees are in tune with the assumptions and beliefs of the organization, the assumptions and beliefs of the organization stay on, which in turn will profoundly impact the values and behaviors of the employees (Ibid).

Organizational culture shapes and directs individuals interact in an organization, Ross Wirth, a senior business administration professor at Franklin University, developed an interpersonal interaction model of organizational culture, which is helpful for us to have a better understanding of organizational culture and behavior. Wirth suggests that the interaction of individual employees in an organization is shaped and directed by power culture, achievement culture, support culture and role culture of the organization. 
Power culture: Strong leaders are needed to distribute resources. Leaders are firm, but fair and generous to loyal followers. If badly managed there is rule by fear, abuse of power for personal gain and political intrigue.

Achievement culture: Rewards results, not unproductive efforts. Work teams are self-directed. Rules and structure serve the system, not an end by themselves. A possible downside is sustaining energy and enthusiasm over time.

Support culture: Employee is valued as a person, as well as a worker. Employee harmony is important. Weakness is a possible internal commitment without an external task focus.

Role culture: Rule of law with clear responsibility and reward system. Provides stability, justice and efficiency. Weakness is impersonal operating procedures and a stifling of creativity and innovation (Wirth, 2009).

Organizational culture exists on multiple levels and it enhances success. Organizational culture provides a hierarchy for decision-making and sets the standards for employees' cooperation and divisions of labor. With the organizational culture the operation is in order; without organizational culture the operation will be in chaos. Clearly, culture can play an important role in an organization. Ever since early explorations of culture, researchers have identified a number of significant consequences for this elusive and intangible force (Trice and Beyer, 1993).

Management of collective uncertainties: Culture can help reduce ambiguity and help employees tolerate and adapt to uncertainties that exist in their environment. To that end, culture helps to clarify behavioral expectations and increase understanding of rules that guide day-today behavior in the workplace.

Creation of social order: Culture defines proper ways to behave and causes members of a group to condemn violations of accepted norms. It defines the rules of the game and serves as a control mechanism that guides the attitudes and behavior of employees.

Creation of continuity: Cultural beliefs and practices are continually passed from member to member through a process known as socialization, organizational practices which help to ensure the acceptance and maintenance of an organization's core values. This process greatly enhances a social systems stability.
Creation of collective identity and commitment: Culture provides a sense of identity as people associate with their organization's mission and feel a sense of attachment to something larger than their own individual self interest.

Although each organization has its own unique culture, some common characteristics have been suggested by researchers. Some of the core characteristic that have been identified in the literature include (Martin, 1996): (1) sensitivity to customer needs; (2) desire to have employees generate innovative ideas; (3) willingness to take risks; (4) value placed on people; (5) open communication and (6) friendliness and congeniality among coworkers.

Alternatively, one unique approach for identifying core organizational values, the competing values framework, identifies two key dimensions that help to distinguish between cultures: (1) control orientationthe extent to which an organization values stabability, order and control (high control), as opposed to valuing flexibility and discretion (low control) and (2) external orientation-the degree to which an organization values what's going on in their external environment, as opposed to valuing internal affairs.

Combining both dimension reveal four possible types of organizational culture. As seen in Fig. 2, the clan culture in the lower left has a strong internal focus (low external orientation) along with a low control orientation. These organizations are characterized by a high degree of flexibility and discretion, providing a very informal, empowering and cohesive work environment. With its strong internal focus, clan cultures focus on teamwork and employee involvement, turning their attention inward to employee excellence and the overall well-being of the workforce. Frequently viewed as very enjoyable places to work, clan cultures tend to be preferred over any other form of culture (Freiberg and Freiberg, 1998).

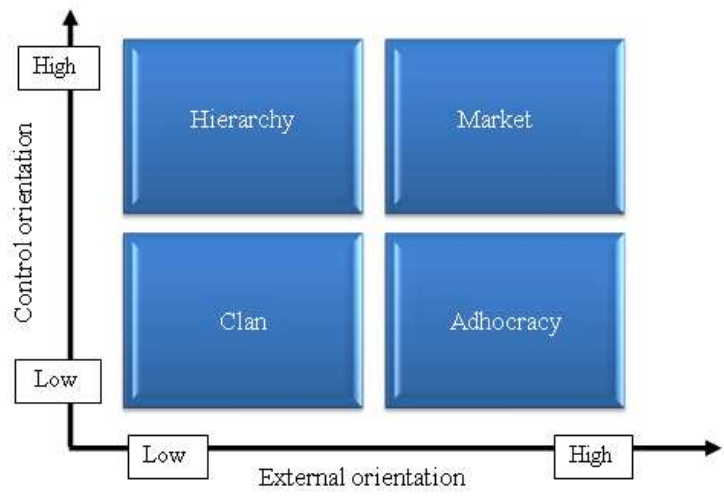

Fig. 2: Competing values framework Cameron and Quinn (1999) 
The adhocracy culture in the lower right emphasizes low control and pays a great deal of attention to the external environment. These organizations have the ability to adapt to and manage specific situational demands created by external forces in their environment and respond quickly to threats to their competitive advantage brought on by market forces. Initiative, flexibility and individual discretion tend to foster a culture of experimentation and innovation, as employees are encouraged to be creative and take risks. Adhocracy cultures rely heavily on an entrepreneurial spirit among its employees as a means to help secure the organization's growth and long term survival.

Organizations with a hierarchy culture emphasize low external focus and maintain a high control orientation. These organizations have a well-articulated command and control structure, maintaining a high degree of formality and hierarchical coordination. Many of the characteristics of this culture are analogous to the organizational form described by Max Weber known as a bureaucracy. As in a hierarchy culture, Weber believed that effective organizations maintained behavioral norms that support formality by relying on a formal hierarchy; a clear set of rules and strict adherence to well defined standards of behavior. Many large corporations and most local, state and federal governments resemble this kind of culture.

A market culture describes organizations that are external in their orientation and concerned with stability and control. In this kind of culture, external entities (customers, suppliers and regulators) represent a focal point of organizational activity; as persistent attention to market forces (supply and demand, market share and competitive advantage) drive behavioral norms. Core values of competitiveness and productivity are hallmarks of this hard-driving, results-oriented approach. A classic example of a market culture would be General Electric, where Jack Welch articulated a vision that GE should be first or second in every business in which it competed, or exit from that business.

An important question remains as to how organizations help to solidify the acceptance of core values that ensure that a culture will maintain itself. Moreover, what organizational practices help employees learn about their organization's culture in the first place? This issues can be described in terms of organizational socialization-the process by which employees come to learn what behaviors are expected of them and how to be effective members of their organization. Although the most critical socialization stage occurs at the time of entry into the organization, employees are exposed to mechanisms that transmit cultural values throughout their entire organizational career. Tools used to socialize members represent a vitally important resource for both creating and sustain a culture throughout the life of an organization.

Organizational behavior is the study of how individuals behave in an organization. It is one of the key areas in the field of management. Organizational behavior studies focus on the behaviors of individuals but are restricted to the behaviors displayed by individuals in the organization. Organizational behavior deals with the overt and covert behaviors of employees and their response to certain stimuli. It also studies an important branch of group and team dynamics. The point of studying organizational behavior by managers is to understand the behaviors of employees, why they behave in a particular way and look for ways in which wrong employee behaviors can be improved. Organizational culture and behavior are quite interrelated as organizational culture influences behavior and vice-versa, as such it is very important that a good and health organizational culture to be created and followed by all the members of an organization together. Managerial staff is responsible for creating a good organizational culture through organizational leadership which is harmonious, symbiotic and realistic. A good organizational culture based on mutual respect fosters and enables teamwork and efficiency (Kulkarni, 2009).

What are the mechanisms by which organizations transmit culture and socialize the workforce? Figure 3 describes the socialization process in terms of several key organizational elements, including organizational processes, reinforcing folklore, archival statements, corporate events, visible behaviors and other visible artifacts.

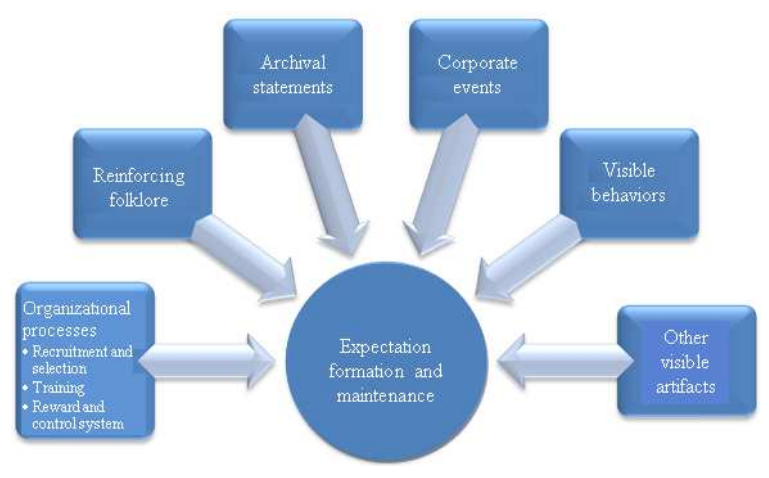

Fig. 3: Tools for transmitting culture and organizational socialization 
Organizational processes includes all of the cultural learning that takes place as a result of key organizational process. Decisions that are made relative to who an organization hires, how employees are trained, how compensation is determined, among others, reveal what's important to an organization and how much value is placed on it. For example, the recruitment and selection process screens out those job applicants who do not "fit" the existing culture. A realistic job preview further promotes a good "fit" by giving recruits a realistic or accurate picture of the job/organization, allowing applicants the opportunity to self-select out of the running when organizational expectations don't suit them. The training function outlines expectations relative to one's task, thereby reduces the likelihood of role ambiguity and role conflict. Lastly, reward and control systems reveal what operational results will be measured and what individual performance will be rewarded. Together, these processes help shape employee expectations about what their organization considers most important.

Several other organizational practices provide a means for transmitting and maintaining an organization's culture. Reinforcing folklore are stories and sagas that emphasize the cultural values that an enterprise wants to reinforce. An example may be found at E.I. Dupont, where employees are told tales about employees who were injured on the job because of a safety violation or carelessness. Archival statements correspond to written assertions of an organization's beliefs and values and are delivered in a variety of formats, including: an employee handbook, a policy and procedures manual, or an explicitly written statement of principle. Corporate events commemorate corporate values by using ceremonies or special events as a way to validate an organization's culture. Visible behaviors transmit cultural values through directly observable behaviors such as decision-making styles, leadership behaviors, manners of address, emotional displays or other directly observable patterns of human activity. Finally, culture can also be transmitted through other visible artifacts, material symbols that send messages about important aspects of an organization's culture. For example, in the education services industry, faculty offices are typically adorned with books and academic certifications, emphasizing the value placed on learning and knowledge acquisition. Taken together, all of the cultural elements identified in Fig. 3 help employees better understand their identity as a group and assist in the formation and maintenance of important expectations in a social system.

Although different in meaning, organizational culture and behavior function as two very important aspects of people management. Organizational culture and behavior can be used by the management to improve the efficiency and the productivity of employees in an organization. Organizational behavior is the art and science which advocates that there can indeed be mutual satisfaction between employees and the management as opposed to the old notion that these two parties are always at loggerheads due to disparate visions. Although anthropological approach to organizational culture and behavior is still under its development, it has been widely applied in business practice. Moreover, various theories have been suggested for organizational culture and behavior, which describe the various models of organizational systems. Organizational systems have been modified over time to ensure employee satisfaction and organizational progress along with organizational culture. Organizational culture and behavior demonstrate that a shared vision and employee motivation leads an organization towards success.

Management of cultural differences: Anthropological research discovered that when people faced by interaction that they do not understand, they tend to interpret the others involved as "abnormal", "weird" or "wrong". It is no doubt that in today's business environment employees of any business organizations are consisted of individuals with different cultural backgrounds. To be aware of cultural differences and to recognize where cultural differences are at work is the first step toward understanding each other and establishing a positive and friendly working atmosphere. For managerial staff there are two important immediate homework when manage cultural differences, which are (1) to use the cultural differences to challenge one's own assumptions about the "right" way of doing things and (2) to use cultural difference as a chance to learn new ways to solve problems (Kevin and Black, 1993).

An organization's culture is often a reflection of the assumptions, values and ideals of the founder or other top managers. Ideally, as a company grows, it attracts and selects managers and employees who share these values. From a management perspective, as people buy into a common set of norms and values, they behave in a way that greatly facilities cooperation among managers. As a result, by helping to establish and maintain effective working relationships among its members, culture can greatly strengthen the internal integration of the organization. Further, once individuals internalize and learn the norms and values of the culture, direct supervision becomes less important as shared norms and values control behavior 
and motivate employees. Following this line of reasoning, culture provides a stable social system and reduces the need for formal and bureaucratic controls, as individuals internalize values which subsequently direct and guide their actions.

It is reasonable to expect, however, that an organization's culture would be more than just the sole product of the norms and values of its leadership team. In addition to the influence of top management, widely held assumptions have often been traced to the larger culture of the corporation's host society (Hofstede and Bond, 1991). In fact, a substantial body of research exists on identifying how distinct national cultures, customs and societal norms of a county might be expressed in work organizations in different countries. For instance, a common problem experienced by American supervisors in some Asian countries stems from a difference in how they approach the supervisorsubordinate relationship. In many Asian countries, protecting the superior's face is a top priority. Conversely, a manager who comes from an American pragmatic tradition takes it for granted that solving a problem always has the highest priority (Schein, 1985). In the end, the dominant values of a national culture are reflected in the constraints or assumptions a manager would impose on his or her subordinates. These societal-level differences produce divergent expectations that would have a significant impact on the ability of an organization to realize a strong corporate identify and collective commitment.

How effectively one can manage the cultural difference is determined by one's cultural intelligence. In fact, cultural intelligence has become a hot topic within management and organizational behavior, which refers to the understanding of the impact of an individual's cultural background on his or her behavior is essential for effective business operation and moreover, cultural intelligence can be used to measure an individual's ability to engage successfully in any environment or social setting. Thomas and Inkson argue that to raise one's cultural intelligence is the key point for effective management of cultural difference. They define the concept of cultural intelligence as the capability to interact with people from different cultural backgrounds. The culturally intelligent managers are able to draw upon their experience and knowledge of cultures to solve the problems or conflicts among individuals with different cultural values (Tomas and Inkson, 2004).

Cultural intelligence was initially described and discussed by Earley and Ang (2003) in their book cultural intelligence: Individual interactions across cultures published in 2003 by Stanford University Press. Behavioral, cognitive and motivational aspects are central to their cultural intelligence framework. They define cultural intelligence as a person's capability to adapt to new cultural contexts. By integrating multi-disciplinary perspectives, research data and practical applications, Earley and Ang (2003) made significant contribution to organizational behavior literature. Their key objective is to address the reasons why people fail to adjust to and understand new cultures (Earley and Ang, 2003).

Cultural intelligence studies focus on strategies to improve cultural perception in order to distinguish behaviors driven by culture from those specific to an individual, it suggests that allowing knowledge and appreciation of the difference to guide responses results in better business practice. Thomas and Inkson indicate that individuals can be more culturally intelligent through learning (Tomas and Inkson, 2004). Earley and Mosakowski (2004) in their article "Cultural Intelligence" published in the October 2004 issue of Harvard Business Review further described cultural intelligence. According to them, cultural intelligence is developed through: (1) cognitive means, learning about one's own and other cultures and cultural diversity; (2) physical means, using one's senses and adapting his or her movements and body language to blend in and (3) motivational means, gaining rewards and strength from acceptance and success. Cultural intelligence is measured on a scale, similar to that used to measure an individual's intelligence quotient. Those with higher cultural intelligence are regarded as better able to successfully blend in to any environment, using more effective business practices, than those with a lower cultural intelligence (Earley and Mosakowski, 2004).

As humans we will always be faced with the "Them Vs US" survival instinct. We see it every day in the news. It is a fundamental part of who and what we are. To overcome this, we need to become open to the differences and accepting of these differences. What we discover is that we are not so different after all. We all need food, shelter, love, kindness, something to believe in and finally, acceptance. This can be hard to accomplish if we are always beating our chests, so stop and listen, really listen. It is ok to disagree or have a different view point, but accept it and move forward is more important (Salier, 2009). One useful framework that examines values that differentiate national cultures identifies five work-related dimensions: Individualismcollectivism, power distance, uncertainty avoidance, masculinity/femininity and long-term orientation (Hofstede et al., 2005):

- Individualism-collectivism is the tendency for individuals to either look after themselves 
(individualistic), or to focus more on the concerns of their group (collectivistic). Individualistic cultures include countries like the United States, Canada, New Zealand, the United Kingdom and Australia, while collectivistic societies include Japan, China, Venezuela and Indonesia

- Power distance relates to the extent to which a society tolerates large inequalities in status and power between its members. Countries that are considered high in power distance include Argentina, India, Malaysia, Mexico and the Philippines, while those that are low in power distance include Finland, Israel, Norway and Sweden

- Uncertainty avoidance relates to the extent to which a culture attempts to minimize ambiguity and reduce uncertainty; seeking more orderliness, formalized procedures and structured lifestyles. High uncertainty avoidance countries include Japan, Sweden and Germany, whereas the United States and Canada have a much stronger tolerance for ambiguity and uncertainty

- Masculinity/femininity relates to the balance between traditional notions of masculinity (e.g., ambition and achievement) verses femininity (e.g., nurturance and interpersonal harmony). Japan, Austria and Italy, are typically viewed as masculine-dominated cultures while Denmark, Costa Rica and Finland represent femininedominated cultures

- Long-term orientation reveals the extent to which a country is oriented towards the future subscribing to values of sustained commitments, perseverance and saving resources. These countries include China, Japan, India and the Netherlands. Societies with a short-term orientation include Canada, Czech Republic, Pakistan and Spain

How can an organization overcome these diverse influences and enhance collective commitment to a broadly and deeply shared value system? Clearly, by paying attention to the critical differences between people from different ethnic or cultural backgrounds and by adjusting behavior accordingly, individuals can interact more effectively with people from different cultures. Moreover, by being sensitive to national culture differences, managers can ensure that their actions don't violate common assumptions in the underlying national culture, thereby allowing them to identify some common ground and develop a shared set of core values. The literature identifies 5 developmental stages for enhancing one's ability to interface with diverse members of their organization (Tomas and Inkson, 2004):
- Reactivity to external stimuli. Avoid blindly adhere to one's own cultural rules and norms. Be open to the possibility that circumstances may have changed

- Recognition of other cultural norms and motivation to learn more about them. Be mindful of deviations from the status quo. Continually attending to cues provided by other people, situations and cultures

- Accommodation of other cultural norms. Increased comprehension and recognition of appropriate behavioral responses to different cultural situations

- Assimilation of diverse cultural norms into alternative behaviors. Select behaviors that match specific cultural situations

- Proactivity in cultural behavior. Attend to the nuances of intercultural interactions and adjust behavior to facilitate better intercultural interactions

As mentioned above, in today's world, almost every business organization must face the reality that its employees are with different cultural backgrounds; as such it is very common that business firms often establish multicultural teams for specific tasks. Cultural differences in multicultural teams can create misunderstandings between team members before they have had a chance to establish any credibility with each other. Research indicates that there is a strong correlation between components of trust (such as communication effectiveness, conflict management and rapport) and productivity. Thus, building trust is a critical step in creation and development of multicultural teams (Asherman et al., 2000).

Cultural differences play a key role in the creation of trust, since trust is built in different ways and means different things in different cultures. For instance, in the US, trust is "demonstrated performance over time" and therefore individuals can gain the trust of their colleagues by coming through and delivering on time with the commitments. In many other parts of the world, such as in Arab, Asian and Latin American countries, building relationships is a pre-requisite for professional interactions. Building trust in these countries often involves lengthy discussions on nonprofessional topics and shared meals in restaurants. Work-related discussions start only once they have become comfortable with the counterpart as individual persons (Gesteland, 2002). Manager of a multicultural team needs to recognize that building trust between different people is a complex process, since each culture has its own way of building trust and its own interpretation of what trust is. 


\section{CONCLUSION}

Culture is deeply rooted in the life of each organization member and exerts tremendous influence on a variety of day-to-day activities, like: how decisions are made, how resources are allocated, who gets promoted and what behaviors are considered appropriate. As such, culture can have a profound impact on outcomes that are vitally important to an organization, including: job satisfaction, turnover, productivity and profitability. Clearly, if cultures are such powerful influencers of behavior, managers must work hard to understand and manage them. To that end, both ideational and adaptationist definitions provide a useful starting point for enhancing one's understanding of organizational culture. From a practical standpoint, building an awareness of both visible and invisible manifestations of culture is an important first step in determining how to manage this key institutional resource.

This study reveals how differences between individuals inside an organization can have a significant impact on the maintenance of effective working relationship among members of that organization. . It also explores the significance of cultural intelligence in management of cultural differences and the means to develop individuals' cultural intelligence. Achieving a good fit between the values of an organization and the values of the employee require not only that an organization hires individuals who are compatible with their culture, but that an organization maintains its culture by removing employees who don't follow the rules of the game. For most organizations, it is a continuous struggle to try to establish and maintain cultural stability and order. This constant state of flux makes cultural diagnosis somewhat challenging. In spite of these challenges, many organizations are still able to achieve strong consistency and widespread agreement with respect to the core elements of culture. The stronger the shared commitment to a core set of values, the more likely these values will shape the preferences and actions of people in an organization.

\section{REFERENCES}

Allaire, Y. and M.E. Firsirotu, 1984. Theories of organizational culture. Org. Stud., 5: 193-226.

Asherman, I., J.W. Bing and L. Laroche, 2000. Building Trust across Cultural Boundaries. Regulatory Affairs Focus, pp: 7-10.

Beals, R.L. and H. Hoijer, 1953. An introduction to Anthropology. Macmillan, New York, pp: 210.
Berger, A.A., 1992. Reading matter: Multidisciplinary perspectives on material culture. Transaction Publishers, New Brunswick, NJ., pp: 148.

Bickman, L. and D.J. Rog, 2009. The Sage Handbook of Applied Social Research Methods. 2nd Edn., SAGE Publications, Inc., Thousand Oaks, California, pp: 661.

Cameron, K.S. and R.E. Quinn, 1999. Diagnosing and Changing Organizational Culture. AddisonWesley, Reading, Mass, ISBN: 0201338718, pp: 221.

Charles, R.E. and R.G. Tian, 2003. The effect of cultural differences on the effectiveness of advertising appeals: A comparison between China and the US. J. Transformat. Bus. Econ., 2: 48-59.

Dansereau, F. and J.A. Alutto, 1990. In Organizational Climate and Culture. Jossey-Bass, San Francisco, CA., pp: 217.

Deal, T. and A. Kennedy, 1982. Corporate Cultures: The Rites and Rituals of Corporate Life. Pengin, Hamondsworth, pp: 232.

Durkheim, E., 1938. The Rules of the Sociological Method. Free Press, New York.

Earley, C. and S. Ang, 2003. Cultural Intelligence: Individual Interactions across Cultures. Stanford University Press, Stanford, CA., ISBN: 9780804743129, pp: 379.

Earley, C. and E. Mosakowski, 2004. Cultural Intelligence. Harvard Business Review, pp: 139-146.

Erchak, G.M., 1998. The Anthropology of Self and Behavior. Rutgers University Press, New Brunswick, New Jersey, pp: 210.

Ferraro, G.P., 2005. The Cultural Dimension of International Business. 5th Edn., Pearson Prentice Hall, Upper Saddle River, New Jersey, ISBN: 10: 0131927671, pp: 224.

Feldhusen, M., 2008. The social life of objects: Interpreting our material culture. Art Educ., 61: 25-32.

Freiberg, K. and J. Freiberg, 1998. Nuts: Southwest Airlines' Crazy Recipe for Business and Personal Success. Broadway, New York, ISBN: 10: 0767901843, pp: 384.

Geertz, C., 1973. The Interpretation of Culture. Basic Books, New York, pp: 470.

Gesteland, R.R., 2002. Cross-Cultural Business Behavior: Marketing, Negotiating, Sourcing and Managing Across Cultures. 3rd Edn., Copenhangen Business School Press, Denmark, ISBN: 9788763000932, pp: 310.

Harris, M., 1968. The Rise of Anthropological Theory. Thomas Y. Crowell, New York, pp: 824.

Hofstede G., 1980. Cultural Consequences, Sage Publications, Newbury Park, CA. 
Hofstede, G. and M.H. Bond, 1991. The confucius connection: From cultural roots to economic growth. Org. Dyn., 16: 4-21.

Hofstede, G., G.H. Hofstede and G.J. Hofstede, 2005. Cultures and Organizations: Software of the Mind. 2nd Edn., McGraw-Hill, New York, ISBN: 0071439595, pp: 434.

Kulkarni, A., 2009. Organizational culture and behavior.

http://www.buzzle.com/articles/organizationalculture-and-behavior.html

Keesing, R., 1974. Theories of culture. Annu. Rev. Anthropol., 3: 73-97.

Kevin, A. and P. Black, 1993. Conflict resolution in intercultural settings: Problems and Prospects. In: Conflict Resolution Theory and Practice: Integration and Application, Sandole, D.J.D. and H. van der Merwe (Eds.). Manchester University Press, Manchester, England, pp: 131-145.

Kroeber, A.L. and C. Kluckhohn, 1952. Culture: A Critical Review of Concepts and Definitions. The Museum, New York, pp: 223.

Lillis, M.P. and R.G. Tian, 2009. Cross-cultural communication and emotional intelligence. Market. Intell. Plann., 27: 428-438. DOI: 10.1108/02634500910955272

Louis, M.R., 1985. An Investigator's Guide to Workplace Culture. In: Organizational Culture, Frost, P.J., L.F. Moore, M.R. Louis, C.C. Lundberg and J. Martin (Eds.). Sage, Newbury Park, CA., pp: 73-93.

Martin, J., 1996. Cultures in Organizations. Oxford University Press, New York, ISBN: 9780195071641, pp: 240.

Mariampolski, H., 2005. Ethnography for Marketers: A Guide to Consumer Immersion. Sage Publications, Newbury Park, CA., ISBN: 10: 0761969470, pp: 264.

Matsumoto, D., 2006. Culture and Nonverbal Behavior. In: Handbook of Nonverbal Communication, Manusov, V. and M. Patterson (Eds.). Sage, Thousand Oaks, CA., pp: 219-236.

Murphy, M.F. and M.L. Margolis, 1995. Science, Materialism and the Study of Culture. University of Florida Press, Gainesville, pp: 223.

O'Neil, D., 2009. Human culture: An introduction to the characteristics of culture and the methods used by anthropologists to study it. http://anthro.palomar.edu/culture/Default.htm

Osgood, C., 1951a. Culture: Its empirical and nonempirical character. Southwestern J. Anthropol., 7: 202-214.
Osgood, C., 1951b. The Koreans and Their Culture. Ronald Press Co., New York, pp: 387.

Ott, S.J., 1989. The Organizational Culture Perspective. Dorsey Press, Chicago, ISBN: 10: 0534109187, pp: 231.

Pettigrew, A., 1979. On Studying Organizational Cultures. In: Qualitative Methodology, Maanen, J.B. (Ed.). Sage, Beverly Hills, California, pp: 570-581.

Peters, T.J. and R.H. Jr. Waterman, 1986. In Search of Excellence. Lessons from American's Best-Run Companies. Harper and Row, New York.

Prown, J.D., 2001. Mind in matter: In Art as evidence. Yale University Press, New Haven, CT.

Rousseau, D.M., 1990. Assessing Organizational Culture: The Case for Multiple Methods. In: Organizational Climate and Culture, Schneider, B. (Ed.). Jossey-Bass, San Francisco, CA., USA., pp: 153-192.

Salier, R., 2009. Personal communication with coauthor Robert Tian.

Schein, E.H., 1984. Suppose we took culture seriously. Academy of Management OD Newsletter, No. Summer, pp: 2-3.

Schein, E., 1985. Organizational Culture and Leadership. Bass, San Francisco, CA., pp: 25.

Schein, E.H., 1990. Organizational culture. Am. Psychol., 45: 109-119.

Schein, E.H., 1993. Organizational Culture and Leadership. 2nd Edn., Jossey-Bass.

Schlereth, T., 1985. Material Culture and Cultural Research. In: Material Culture: A Research Guide, Schlereth, T. (Ed.). University Press of Kansas, Lawrence, KS., pp: 1-34.

Schlereth, T.J., 1999. Material Culture Studies in America, 1876-1976. AltaMira Press, Oxford, pp: $1-78$.

Serrie, H., 1986. Anthropology and International Business. College of Williams and Mary, Williamsburg, VA., pp: 286.

Taylor, W.W., 1948. A Study of Archeology. American Anthropological Association Memoir No. 69, pp: 256.

Tomas, D.C. and K. Inkson, 2004. Cultural Intelligence: People Skills for Global Business. 4th Edn., Berrett-Koehler Publishers, Inc., San Francisco, CA., ISBN: 1576752569, pp: 222.

Trice, H.M. and J.M. Beyer, 1993. The Cultures of Work Organizations. Prentice Hall, Inc., Englewood Cliffs, New Jersey, ISBN: 9780131914384, pp: 510.

Triandis, H.C., 1972. The Analysis of Subjective Culture: An Approach to Cross-Cultural Social Psychology. John Wiley and Sons Inc., New York, ISBN: 10: 0471889059, pp: 398. 
Tylor, E.B., 1974. Primitive Culture: Researches into the Development of Mythology, Philosophy, Religion, Language, Art and Custom. Gordon Press, New York, ISBN: 10: 0879680911.

Walle, A.H., 2001. Qualitative Research in Intelligence and Marketing. Quorum Books, Westport, CT., pp: 246.

Weller, S. and A.K. Romney, 1988. Systematic Data Collection. 1st Edn., Sage Publications, Newbury Park, CA., ISBN: 9780803930742 , pp: 96.

Wikipedia, 2009. Culture. http://en.wikipedia.org/w/index.php?title=Culture \& oldid $=324525118$
Wirth, R., 2009. Business culture. http://www.entarga.com/stratplan/culture.htm

Whilte, L.A. 1959. The concept of culture. Am. Anthropol., 61: 227-251.

Wright, S., 1994. Anthropology of Organizations. Routledge, New York, ISBN: 9780415087476, pp: 225. 